\title{
Implementação de um currículo mínimo de geografia para as escolas estaduais do Rio de Janeiro
}

\author{
Saulo Cezar Guimarães Farias ${ }^{1}$
}

${ }^{1}$ Universidade do Estado do Rio de Janeiro. R. São Francisco Xavier, 524 - Maracanã - Rio de Janeiro - RJ. E-mail: saulocg@bol.com.br.

Recebido em 04/2013. Aceito para publicação em 05/2013.

Versão online publicada em 08/11/2013 (http://seer.ufrgs.br/paraonde)

\begin{abstract}
Resumo - 0 presente trabalho realizou uma breve análise sobre a implementação do currículo mínimo de geografia nas escolas estaduais do Rio de Janeiro entre os anos 2010 e 2012. Também reconstituiu os percalços que a educação brasileira sofreu nas últimas décadas e as tentativas políticas recentes de reverter o atraso e melhorar a qualidade da educação básica no Brasil. Partindo de uma estratégia metodológica teórica-descritiva, baseou-se em documentos e experiências de professores participantes do projeto, concluindo que o mesmo se configurou em uma medida paliativa sem grandes resultados para a melhora da educação estadual.

Palavras-chave: Currículo. Geografia. Políticas públicas. Educação.
\end{abstract}

\section{Introdução}

As publicações científicas que se debruçam sobre análises de formação e composição de currículos das disciplinas elementares da educação básica, apresentam peculiaridades semelhantes. São debates sobre falta ou excesso de conteúdos, ambiguidades, propósitos e até mesmo, questões oriundas de grandes discussões acadêmicas que perpassam o espaço universitário e chegam às salas de aula.

Analisando as mais recentes críticas sobre a formulação do currículo de geografia, é percebido um consenso entre autores como Rocha (1996), Costa (2012), Saviani (1996) e Capel (1988) afirmando que as significativas transformações políticas, sociais e educacionais ocorridas nas décadas de 1970, 1980 e 1990 não conseguiram estabelecer um currículo geográfico mais crítico e reflexivo, um currículo mais claro e atento e relacionando os problemas físicos, políticos e econômicos mundiais com as questões sociais. Segundo Saviani (1996), "a planejada ampla discussão não aconteceu, pelo menos de forma democrática, de maneira que os parâmetros ficaram aquém do esperado, os textos extremamente teóricos, e, em alguns trechos, detalhistas demais e ambíguos".

Toda essa discussão retornou recentemente ao universo educacional do Estado do Rio de Janeiro após o fracasso, nas avaliações internas ${ }^{1}$, das instituições de ensino do Estado. Apesar dos resultados inicialmente contemplarem as disciplinas de matemática e português o governo estadual criou projetos pedagógicos envolvendo todas as disciplinas da grade curricular da educação básica e políticas de gestão e administração direcionadas ao pessoal administrativo, alunos e pro- fessores da rede estadual de ensino, para tentar recolocar o Rio de Janeiro entre as cinco melhores redes estaduais de educação do país.

Contudo, quais benefícios reias para a educação carioca a criação de um currículo mínimo unificado para todas as escolas da rede estadual traria? Qual o maior interesse do governo do Estado em criar tal política pública? As críticas e sugestões dadas pelos professores nas escutas e audiências foram levadas em consideração na determinação do currículo?

Nesta pesquisa foi analisada uma política de governo carioca estruturada em ações fragmentadas por áreas, apoiadas pelo consórcio CEDERJ e a Fundação CECIERJ tendo atenção especial para a construção do currículo da disciplina geografia no ensino fundamental e médio regular (Currículo Mínimo-CM).

Partindo de uma análise teórico-metodológica descritiva abrangendo os percalços da educação brasileira até a contemporaneidade, as dificuldades encontradas para a definição de um currículo de geografia que atendesse as necessidades e objetivos do ensino da disciplina para a população, a pesquisa servirá de parâmetro para o entendimento destas discussões.

\section{Transformações políticas e educacionais brasilei- ras}

A nova configuração econômica nacional requisitou um aumento da qualidade dos serviços públicos prestados a população. A educação em todas as suas esferas, níveis e modalidades foi considerada a pedra fundamental para estruturar o desenvolvimento pelo qual o país estava passando (PERONI, 2003).

${ }^{1}$ As avaliações que compõem o SAEB são realizadas a cada dois anos, quando são aplicadas provas de Língua Portuguesa e Matemática, além de questionários socioeconômicos aos alunos participantes e à comunidade escolar. 
De tanta visibilidade (muita dela conseguida pelo caos vivido pela educação pública brasileira nas últimas décadas), passou a ser parte prioritária das plataformas políticas dos partidos, nas eleições de todos os entes federados do país nos últimos anos. Os discursos e promessas feitas pelos políticos por melhores condições de acesso, permanência e conclusão à educação básica para a população, passaram a ser tão envolventes que fizeram parecer que o país caminharia na direção de resolver, em pouco tempo, um problema tão antigo na história dos estados e municípios.

Essa realidade passou a ser detectada conjuntamente com a estabilização da economia brasileira nas últimas duas décadas do século XX e início do século XXI, tomando forma de políticas públicas federais, como por exemplo, a ampliação e redistribuição dos recursos para a educação com a criação do FUNDEF, o Fundo de Manutenção e Desenvolvimento da Educação Básica e de Valorização dos Profissionais da Educação que posteriormente tornou-se FUNDEB, atendendo toda a educação básica (PERONI, 2003, SOUZA, 2003).

\section{Segundo Souza (2010, p. 3):}

Com a estabilidade monetária, trazida pelo Plano Real, houve a recuperação da capacidade de programação das escolas públicas. Tentativas de ajuste fiscal, bem-sucedidas ou não, não afetam substancialmente os gastos educacionais planejados. Cresceu o número de empréstimos externos contratados junto ao Banco Mundial, destinados principalmente ao ensino fundamental, e junto ao Banco Interamericano de Desenvolvimento, para o ensino médio. Isto porque o governo federal era capaz de oferecer a contrapartida de recursos nacionais sem os atrasos costumeiros. Estes empréstimos significaram um aumento de recursos para a educação básica e permitiram concentrar sua utilização em ações prioritárias, principalmente em áreas pobres do Nordeste.

Enquanto a educação era elevada a patamares mais altos das pretensões políticas, os embates e discussões teórico-conceituais sobre a temática também se acentuavam dentro e fora dos espaços científicos.

Durante todo o processo de desenvolvimento do sistema educacional brasileiro pós economia estabilizada, as políticas públicas e de governo direcionadas para a educação, foram estabelecidas com o intuito de formar um contingente populacional que pudesse satisfazer as necessidades de um país em transformação. Para isso, vultosos investimentos eram direcionados a área, tanto por institutos internacionais de financiamento quanto de repasses de verbas públicas, encami- nhadas de ente federado a ente federado.

Para atender requisitos de instituições de fomento internacionais dando respaldos positivos averiguados por indicadores nacionais como o SAEB, Prova Brasil e elevar a qualidade da educação básica do país, foram implementadas políticas educacionais padronizadas que pudessem equilibrar as grandes diferenças regionais.

No governo do presidente Luiz Inácio Lula da Silva, por intermédio do MEC, foi realizada uma grande reformulação chamada Reforma Educacional dos Anos 90, particularmente pela profusão de normatizações que se seguiram à promulgação da Lei de Diretrizes e Bases (LDB).

Com a promulgação da Constituição Federal de 1988 (CF) e início do processo de descentralização da do poder político-adminsitrativo no país, os estados e municípios puderam criar sistemas educacionais mais autônomos e iniciar o século XXI com políticas públicas educacionais mais específicas atendendo as exigências das populações locais. Essa nova realidade pôde proporcionar as escolas maior liberdade para discutir suas ementas e discutir os currículos das disciplinas.

Contudo, esse novo cenário educacional apresentava o grande desafio que não se constituía em somente discutir as questões apresentadas no currículo oficial, deveriam ir muito além.

\section{A ciência geográfica, o currículo e as necessidades contemporâneas}

A concepção da ciência geográfica brasileira está atrelada há uma conjuntura de fatores históricos congruentes a da própria formulação das estruturas de ensino do país.

O surgimento da geografia enquanto disciplina autônoma do currículo nacional se deu a partir de 1837 quando o Decreto de 2 de dezembro daquele ano, expedido pela Regência Interina, criava o Imperial Colégio de Pedro II, localizado no Rio de Janeiro.

As elites brasileiras, que postulavam um ensino de maior qualidade em todo território do império, não "pestanejaram" em implantar um modelo estrangeiro que pudesse servir de eixo por todos os estabelecimentos de ensino, públicos e privados. Era essencial criar um uma referência frente a grande desordem encontrada em alguns níveis educacionais e também estabelecer um padrão de excelência a ser espelhado.

0 modelo francês se tornou o ideal de educação, de organização escolar, da forma, bem como o direcionador dos conteúdos adotados pelas disciplinas. Durante todo período imperial o ensino da geografia foi uma transcrição de tudo que surgia na França, com ou

\footnotetext{
${ }^{2}$ Criado em 2000, com o objetivo de levar educação superior, gratuita e de qualidade a todo o Estado do Rio de Janeiro, o Consórcio CEDERJ é formado por sete instituições públicas de ensino superior: CEFET, UENF, UERJ, UFF, UFRJ, UFRRJ e UNIRIO, e conta atualmente com cerca de 26 mil alunos matriculados em seus 12 cursos de graduação a distância.

${ }^{3} \mathrm{~A}$ Fundação CECIERJ desenvolve projetos nas áreas de educação superior à distância e divulgação científica, atingindo diretamente mais de 60 mil pessoas/ano residentes nos 92 municípios do Estado do Rio de Janeiro.
} 
sem nenhuma aplicação a características do país (CHIZZOTTI, 1975; CAPEL, 1988). De acordo com Rocha (1996, p. 2) "não só se estudava no Brasil a geografia considerada interessante, pelo governo francês para ser difundida, como também se faziam os estudos em compêndios franceses".

Inúmeras gerações de estudantes brasileiros aprenderam geografia exclusivamente pelas publicações (manuais e atlas) francesas. Somente nas primeiras décadas do século XX passaríamos a nos afastar do velho modelo de geografia escolar vindo de fora do país.

A década de 20, no entanto, pode ser considerada como um marco de início de profundas transformações na geografia escolar brasileira. Em oposição ao modelo de geografia tradicionalmente ensinado, emerge de forma paradigmática uma nova proposta de ensino para esta disciplina, tornada oficial a partir da reforma implementada por Luiz Alves/Rocha Vaz (ROCHA, 1996, p. 3).

As expectativas por mudanças e as novas discussões sobre as concepções e referenciais das ciências que compunham os currículos nacionais se refletiram em projetos e políticas públicas e também na legislação educacional do início do século passado. Este período também assume grande importância pelo debate entre as duas grandes correntes geográficas preponderantes, a corrente conservadora que defendia uma concepção tradicional da geografia e de seu ensino (a geografia clássica) e a nova corrente de professores, geógrafos e pesquisadores defendendo a renovação do ensino desta disciplina.

De qualquer ponto de vista foi conseguido ou quisto enxergar os ventos favoráveis a reformulações dos modelos, sistemas e tendências educacionais, não foi deixado esquecer que a construção curricular no Brasil não se deu sob uma única ideologia, mas com influência de tendências, objetivos e interesses diferentes, em especial, o currículo geográfico.

Segundo Moreira (1997) a partir da década de 1980, foi possível perceber um hibridismo de discursos críticos e pós-críticos, especialmente em virtude do foco político na teorização crítica e do foco no pós-modernismo. Em relação às teorias pós-críticas estas são utilizadas em virtude de sua análise mais instigante da cultura, capaz de superar divisões hierárquicas, redefinir a compreensão da linguagem e aprofundar o caráter produtivo da cultura, particularmente da cultura escolar (JESUS, 2008).

\section{A criação do currículo mínimo de geografia para as escolas estaduais do Rio de Janeiro}

O sistema educacional brasileiro contemporâneo é fruto de uma gama políticas públicas formuladas por governos com propósitos e interesses muito além e aquém das necessidades do país e da população. Com a criação da CF e com o início do processo de descentralização das políticas públicas no país, os governos subnacionais se articularam e implementaram, em suas gestões, programas educacionais mais específicos e autônomos.

Esse arranjo esperado pelo povo e disposto nos textos da Constituição, favoreceu a criação de políticas públicas e de governo mais precisas, levando em consideração as características locais e a articulação entre as três esferas de governo na implementação das políticas unificadas para atender tais necessidades.

Segundo a Lei de Diretrizes da Educação Nacional-Lei n. 9394/96, artigo $9^{\circ}$ (1996, p. 29).

A União incumbir-se-á de estabelecer, em colaboração com os Estados, Distrito Federal e os Municípios, competências e diretrizes para a Educação Infantil, Ensino Fundamental e o Ensino Médio, que nortearão os currículos e seus conteúdos mínimos de modo a assegurar a formação básica comum.

Vivendo em um mundo globalizado e de certo modo com uma característica cultural unificada, passamos a ter novos problemas que necessitam de novas formas de produção e apropriação dos saberes para resolvê-los. A função da escola contemporânea se tornou maior e mais complicada que as anteriores e para lidar com essas novas particularidades, seria necessário a capacidade de desenvolver nas crianças, adolescentes e jovens habilidades e competências para planejar e resolverem problemas do seu cotidiano.

Apoiado na teoria de competências do sociólogo suíço Philip Perrenoud que dialogavam com as definições do educador suíço Jean Piaget, nas quais a construção do conhecimento ocorre quando acontecem ações físicas ou mentais sobre os objetos, os conceitos de competências e habilidades foram introduzidos formalmente no sistema educacional brasileiro em 1990, com a criação do Sistema de Avaliação da Educação Básica e, posteriormente, em 1998, com a instituição do Exame Nacional do Ensino Médio (ENEM).

Na contramão do chamado "conteudismo", defendia-se que os conteúdos curriculares, sozinhos, não dariam conta da formação dos alunos. Era preciso ensiná-los a usar os conhecimentos aprendidos em sala de aula no mundo em que viviam. A educação por meio de habilidades e competências, inserida nos sistemas educacionais brasileiros, não é exclusividade do país, tem sido implantada em muitos países desenvolvidos com sucesso há bastante tempo.

Contudo, o que realmente ocorre é que o ENEM não desconstruiu o ensino conteudista aplicado na maior parte das escolas públicas e privadas do país. A efetivação do ENEM pulou etapas em seu processo de implementação. Praticamente não houve discussão sobre um problema anterior, que se refere a extenso currículo das disciplinas oferecidas a educação infantil e ensino médio que inviabiliza um ensino contextualizado. 
Mesmo com todas as incoerências e incertezas, o governo do Estado do Rio de Janeiro iniciou uma série de projetos pedagógicos em parceria com a fundação CECIERJ e o consórcio CEDERJ, entre eles, estabelecer um Currículo Mínimo de todas as disciplinas da grade curricular do Ensino Fundamental e Médio (Regular, Normal e Educação de Jovens e Adultos - EJA) das escolas estaduais, construir material de apoio pedagógico para os professores e também cursos à distância de capacitação e aperfeiçoamento de professores da rede. Cabe lembrar que na continuação de novos projetos, a SEEDUC-RJ lançará gradativamente no ano 2013 o Nova EJA, com uma reformulação na proposta de ensino, material didático e capacitação de professores atuantes na modalidade.

o Currículo Mínimo seria uma referência a todas as escolas do Estado, apresentando as competências e habilidades que deveriam ser seguidas nos planos de curso e nas aulas. Sua finalidade principal seria orientar os itens considerados essenciais no processo de ensino-aprendizagem ano de escolaridade e bimestre de modo a garantir uma essência básica comum, alinhada com as atuais necessidades de ensino, identificadas não apenas nas legislações vigentes, Diretrizes e Parâmetros Curriculares Nacionais, mas também nas matrizes de referência dos principais exames nacionais e estaduais.

Assim, é considerado não ser mais necessário um ensino conformista para um trabalho restrito, marcado por normas de obediência a uma disciplina profissional, como nos paradigmas tayloristas-fordistas, mas faz-se a exigência de um ensino sintonizado com competências criativas, mantendo uma relação de correspondência entre educação e exigências do mundo produtivo (COSTA; LOPES, 2012).

A concepção, redação, revisão e consolidação do currículo mínimo foram conduzidas por equipes disciplinares de professores da rede estadual, coordenadas por professores de diversas universidades do Rio de Janeiro, que se reuniram em torno dessa tarefa, a fim de promover um documento que atendesse às diversas necessidades do ensino na rede. Ao longo do período de consolidação, dezenas de comentários e sugestões foram recebidas e consideradas por essas equipes.

A elaboração do currículo mínimo estadual teve duas edições, a primeira editada em 2010 e a atual terminada em 2012. A primeira versão sofreu muitas críticas pelos professores da rede, principalmente por conter ambiguidades e repetições dentro das habilidades e competências. A segunda versão (2012) teve o privilégio de trabalhar em cima de um material já preparado e com todas as críticas à disposição da equipe.

Durante as reuniões conjuntas na Secretaria de Educação do Rio de Janeiro (SEEDUC-RJ/CECIERJ) os professores eram orientados a estabelecer critérios bem definidos para a confecção dos currículos. Esses critérios deveriam servir para orientar e definir os con- teúdos e as habilidades e competências imprescindíveis na sua área e que elas estivessem contempladas nas especificidades e conteúdos programáticos das avaliações federais e estaduais. As reuniões eram marcadas semanalmente em locais previamente combinados e de acordo com as disponibilidades dos integrantes, como podemos ver nas figuras 1 e 2 .
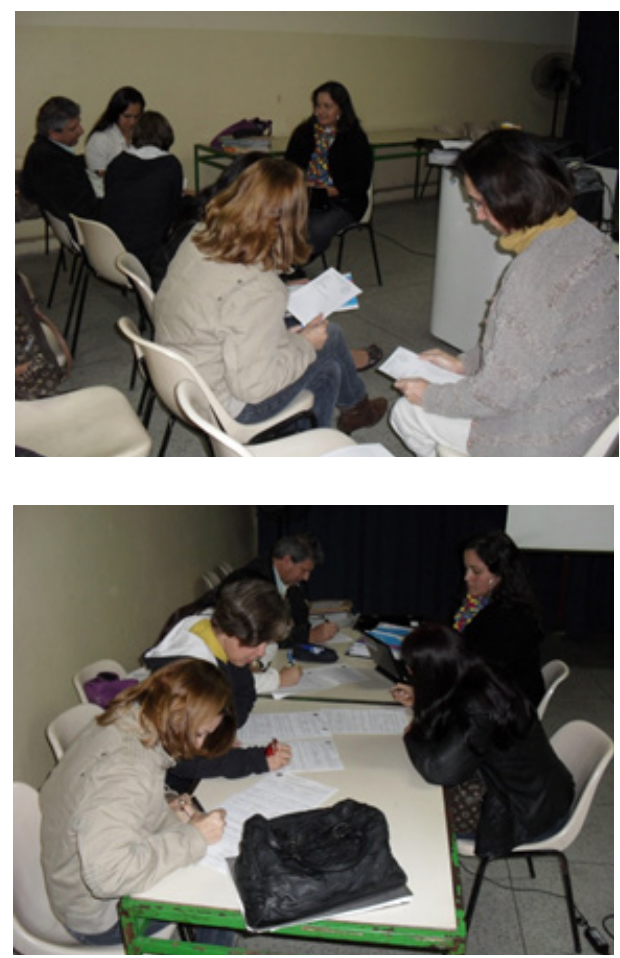

Figuras 1 e 2: Reuniões para confecção do Currículo Mínimo (Coordenadoria Médio Paraíba)

Fonte: Disponível em: http://drpmedioparaiba.webnode.com.br

Após a análise de cada tema, separado por turmas e bimestres do ensino fundamental e médio, era iniciada uma discussão sobre as concepções e abordagens de cada área temática definida e selecionada as consideradas necessárias para a supressão, aglutinação ou melhora da redação da habilidade e competência já estabelecida. Depois de cada alteração necessária o material seguia para a equipe do CECIERJ fazer correções ortográficas e formatar dentro dos padrões de edição.

Ao longo da realização do projeto eram programadas consultas virtuais e audiências presenciais nas sedes das coordenadorias com divulgação pelo site da SEEDUC e nas escolas, convidando os professores para discutir os modelos refeitos pela equipe de professores. Na maior parte delas a presença era baixa (em média 30-40 indivíduos) se comparado com o quadro de professores da respectiva coordenadoria. Esse fato possui muitas explicações entre elas, as reuniões serem em dias de semana e algumas coordenadorias terem municípios muito distantes da sede.

Nas consultas virtuais a equipe teve a oportunidade de observar maior quantidade de comentários, críticas sugestões por ser virtual e com maior facilidade de acesso. Estão entre as críticas mais pertinentes encontradas nos textos resultantes das consultas:

"Acho que ainda não há maturidade para ser tra- 
balhado globalização neste ano (8aano). Deveria-se, ao meu ver,trabalhar as diferentes organizações regionais. Trabalhar conceitos de desenvolvimento e subdesenvolvimento. Os conceitos de socialismo e capitalismo, a Divisão internacional do Trabalho, blocos econômicos". "Acho ilógico, um ano letivo aprendendo só sobre um continente, no caso o Americano, e o 9o ano ficar sobrecarregado com os demais continentes.Sabendo-se que no $7^{\circ}$ ano é Brasil, muita coisa sobre o continente Americano é abordado. Portanto, acho que além da América, poderia ser estudado um segundo continente, no $8^{\circ}$ ano".

Grande parte das críticas da nova edição do CM foi sobre a definição de qual temática teria maior ênfase para fazer parte das habilidades do bimestre. Também foi alvo de críticas a disposição dos conteúdos por bimestre onde os professores afirmavam haver uma descontinuação ou fragmentação do conteúdo com o bimestre seguinte, como exemplo, a determinação do estudo do continente asiático em apenas $2^{\circ}$ bimestres do $9^{\circ}$ ano. Outro ponto bastante discutido foi a introdução da temática "Rio de Janeiro" no $3^{\circ}$ ano do Ensino Médio como podemos ver a seguir:

"Não concordo com o 4ํㅡㄹ bimestre, pois o aluno faz o ENEM e com certeza não cairá questões do Estado do Rio somente. A não ser casos que repercutam no Brasil todo, como a catástrofe na região serrana".

“O conteúdo de 9o ano ficou bem extenso. Contudo, não percebi a inserção da Oceania no $4 \stackrel{0}{ }$ bimestre no interior das competências. Penso que o Oriente Médio poderia ser trabalhado na introdução do estudo do continente asiático já no 30 bimestre (quando se propõe a regionalização da Ásia) e no quarto ficariam as questões relacionadas a Palestina, a formação do Estado judeu, a instabilidade política dos países do Oriente Médio, entre outras".

O objetivo dos encontros não tão somente apontavam possíveis pontos de divergências, mas também tinham o objetivo de identificar pontos positivos e negativos do processo de implementação do Currículo Mínimo de Geografia nas escolas, como também do material de apoio que está disponível no site da SEEDUC.

Cada encontro era organizado pelo grupo de trabalho do setor da Geografia que contou com oito professores dinamizadores e oito polos. Os encontros eram planejados de modo a dar voz aos professores para que eles pudessem trazer a leitura que fizeram do Currículo Mínimo de Geografia nas escolas e apresentar as estratégias utilizadas para a aplicação do CM. A ideia era estimular os professores a falarem das suas práticas, das suas abordagens geográficas, explicitar os desafios e as possibilidades de superá-los, a fim de reconhecermos os grandes entraves.

Entretanto muitos professores se manifestaram negativamente a respeito da organização enfoque e necessidade do CM como podemos ver adiante.
"As habilidades e competências estão bem fracas em alguns pontos. Infelizmente, o tempo até março me falta para sentar com mais calma e analisar todos os pontos e refazê-los. Já afirmo que não é um bom currículo e está cheio de falhas. Fico pasmo que professores ativos tenham cometido tantos erros. Parece que estão completamente desatualizados e basearam a confecção do currículo mínimo na base do "eu acho que".

Quanto à avaliação do material de apoio foi pensado na reflexão sobre a relevância do material, o distanciamento em relação à realidade escolar, clareza do que está sendo proposto, o diálogo com o CM, e sugestões de continuidade do trabalho. Destacou-se a importância de buscar na Antropologia, a base teórica sobre a escuta do outro, no sentido de respeitar e valorizar os diferentes olhares sobre o que foi produzido.

Fato muito relevante constatado durante as reuniões internas e externas, em estabelecimentos de ensino do estado e nas consultas, que muitos professores das escolas públicas não entendem nem mesmo o significado das palavras "habilidades e competências" no contexto da educação, muito menos como aplica-las. As aulas não são preparadas de maneira a desenvolver habilidades e competências nos alunos, quer seja pela falta de estrutura física (recursos multimídia e audiovisuais inclusive) e pedagógica ou pela inadequação do material didático, elaborado fora dos padrões específicos para o desenvolvimento de habilidades e competências. Segundo os relatos abaixo:

"A criação de um currículo mínimo seria louvável na medida em que os alunos do estado teriam uma base comum. A falta de investimentos na rede física das escolas, na formação dos professores, na diminuição da carga horária de geografia torna esse currículo uma farsa na medida em que com apenas dois tempos por semana fica impossível você cumprir todos os conteúdos estipulados pela Secretaria de Educação. Além do tempo temos a obrigatoriedade de dar os conteúdos na medida em que as avaliações externas vão cobrar os mesmos e está atrelada a uma gratificação. Nessas condições os alunos ficam prejudicados na medida que o professor não pode aprofundar os conteúdos estipulados pela SEE. Na medida que as provas externas cobram esses conteúdos e o professor por falta de tempo não pode aprofundar os conteúdos. Temos assim uma eficiente arma de controle do trabalho docente e impede que os nossos alunos tenham aprendizado mais completo e crítico. Além disso temos uma forma sutil de legitimar a privatização da escola pública na medida que com esses currículo mínimo e as provas externas vamos ter a criação de uma lista das piores e melhores escolas e propiciar a entrada de ONGs e projetos milionários nas escolas. A elaboração e aplicação desse currículo tende ao fracas- 
so na medida que as questões básicas acima mencionadas não são resolvidas".

"Ao invés de criar um currículo deveria haver a melhoria da qualidade do livro didático em relação ao conteúdo nele contido e adequação do livro a realidade local da escola pelo menos dentro dos padrões referentes ao estado do rio de janeiro, excesso de conteúdo no que se refere ao currículo mínimo que na realidade não é mínimo é total,faltando tempo necessário para que o professor realize de forma concreta e ampla todo esse conteúdo,pois sempre estamos lutando contra a falta de recursos, talvez com o advento da informática, sendo empregada de forma lúdica e sem exclusão social e digital faça que ocorra uma mudança significativa nesses padrões para que ocorra uma mudança continua”.

A proposta do governo estadual tem como objetivo maior criar um paralelo entre o que é requerido para um bom desempenho em avaliações e indicadores educacionais aplicados no país, com um equilíbrio diante de muitas desigualdades entre as escolas das suas coordenadorias. Entretanto, passou por cima de grandes e profundas discussões acadêmicas sobre formação de currículos e outra ainda maior, encontrada dentro da ciência geográfica e ensino de geografia.

A confecção dos currículos se apresenta com uma dinâmica intensa e sem fim, sendo produzida conforme as exigências da sociedade vigente e tentando equlibrar-se em parâmetros aleatórios. Criar padrões para definição de conteúdos a serem seguidos por qualquer espaço educacional seria um erro, uma ação fadada ao fracasso e alvo das mais variadas críticas.

Observamos que o objetivo da política federal de criar um sistema educacional atual, que atende as novas necessidades de um Brasil inserido no mundo globalizado foi equivocado, pois se iniciou "de trás para frente" deixando de lado outros entraves que provocam instabilidades nos sistemas educacionais.

\section{Considerações finais}

Apesar da grande estrutura formada e dos grandes investimentos estaduais na idealização e execução de projetos educacionais como o do CM, não podemos deixar de constatar que a ação não priorizou as necessidades da educação estadual do Rio de Janeiro carente de tantas outras reformas.

Iniciativas como a criação de sistemas educacionais compactos e eficazes para atender as necessidades políticas de governos são muito comuns no Brasil. 0 universo educacional sempre foi alvo das medidas desesperadas de governos desnorteados e sistemas políticos fracassados e as cosequencias são sentidas em todos os níveis da educação.

Deixar de fora de grandes projetos educacionais as considerações e constatações de décadas de discussão acadêmica faz deles uma simples medida remediadora, sem efeitos na qualidade da educação a médio e longo prazo. Esse fato é recorrente no projeto da SEEDUC-RJ quando em pouco tempo, elegeu um padrão curricular de uma disciplina tão complexa e dinâmica como a geografia.

\section{Implementation of a minimum of geography curri- culum for schools state of Rio de Janeiro}

Abstract - This study conducted a brief analysis on the implementation of the minimum curriculum for geography in the public schools of Rio de Janeiro between 2010 and 2012 . Also reconstituted the mishaps the Brazilian education suffered in recent decades and the recent political attempts to reverse the delay and improve the quality of basic education in Brazil. From a theoretical-methodological strategy descriptive, based on documents and experiences of teachers participating in the project, concluding that even if configured in a palliative measure without great results for improving education statewide.

Keywords: Curriculum. Geography. Public policies. Education.

\section{Implementación de un mínimo de curriculum geo- grafía de las escuelas del estado de Rio de Janeiro}

Resumen - En este estudio se llevó a cabo un breve análisis sobre la aplicación de las enseñanzas mínimas de la geografía en las escuelas públicas de Río de Janeiro entre 2010 y 2012. También se reconstituyeron los percances de la educación brasileña sufrió en las últimas décadas y los recientes intentos políticos para revertir el retraso y mejorar la calidad de la educación básica en Brasil. De una estrategia teórico-metodológica descriptiva, basada en documentos y experiencias de profesores que participan en el proyecto, concluyendo que incluso si se ha configurado en una medida paliativa sin grandes resultados para mejorar la educación en todo el estado.

Palabras clave: Currículo. Geografía. Las políticas públicas. La educación.

\section{Referências}

BRASIL. Ministério de Educação e Cultura. LDB - Lei no 9394/96, de 20 de dezembro de 1996. Estabelece as diretrizes e bases da Educação Nacional. Brasília: MEC, 1996.

BRASIL, Ministério da Educação. Secretaria de Educação Média e Tecnológica - SEMTEC. Parâmetros Curriculares Nacionais para o Ensino Médio. Brasília: EC/ SEMTEC, 4 v.,1999. Disponível em: <www.mec.gov.br>. Acesso em: 01 abr. 2013.

CAPEL, H. Filosofia y ciencia en la geografía contemporánea. $3^{\mathrm{a}}$ ed. Barcelona: Barcanova, 1988.

COSTA, H. H. C.; LOPES, A. C. Políticas de currículo para o ensino de geografia: uma leitura a partir dos PCN para o ensino médio. Revista Contemporânea de Educação. v. 7, n. 14, 2012. 
CHIZZOTTI, A. As origens da instrução pública no Brasil. São Paulo, 1975. (Dissertação de Mestrado) - Pontifícia Universidade Católica de São Paulo.

JESUS, A. R. Currículo e educação: conceito e questões no contexto educacional. Anais do VIII congresso nacional de educação - PUCPR, 2008. Disponível em: <http:// www.pucpr.br/eventos/educere/educere2008/anais/ pdf/642_840.pdf>, Acesso em: 02 abr. 2013.

MOREIRA, A. F. B.; SILVA, T. T. (Org.). Currículo, cultura e sociedade. $2^{\mathrm{a}}$ ed. São Paulo: Cortez, 1997.

ROCHA, G. O. A trajetória da Disciplina Geografia no Currículo Escolar Brasileiro (1837-1942). São Paulo: PUC-SP, 1996. 292p. (Dissertação de Mestrado)
SAVIANI, N. Parâmetros Curriculares Nacionais: O que dispõem para o ensino fundamental. In: I Congresso Nacional de Educação, 1997. Anais do I CONED/96 - Conferências e Mesas Redondas. Belo Horizonte / MG. v. Prog B.

SOUZA, A. M. A Relevância dos Indicadores Educacionais para a Educação Básica: informação e decisões . Rio de Janeiro, v. 2, n. 5, p. 153-179, mai./ago. 2010.

SOUZA, D. B. et al. Desafios da Educação Municipal. Rio de Janeiro: DP\&A, 2003.

PERONI, V. Política educacional e papel do Estado: no Brasil dos anos de 1990. São Paulo - Xamä, 2003. 